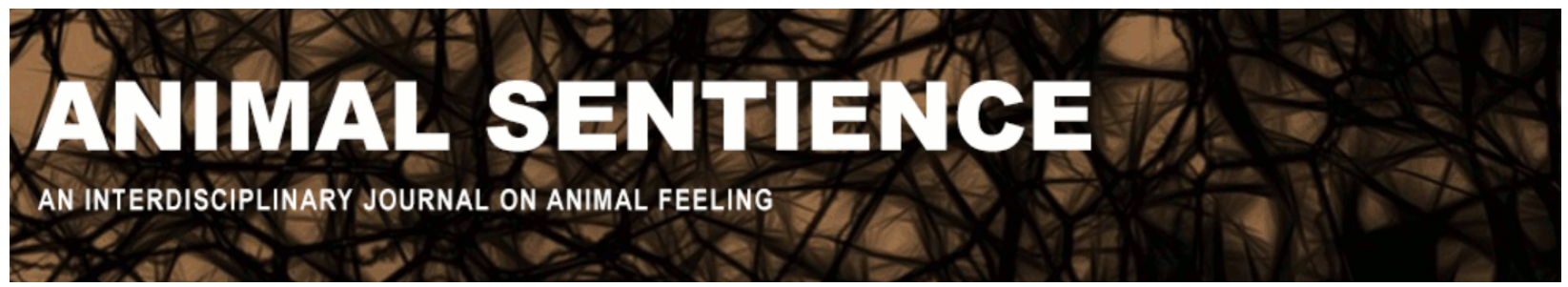

Noël-Guéry, Alix (2019) Octopus sentience: Three criteria. Animal Sentience 26(24)

DOI: $10.51291 / 2377-7478.1514$

Date of submission: 2019-09-04

Date of acceptance: 2019-09-10

(c)

This article has appeared in the journal Animal

Sentience, a peer-reviewed journal on animal

cognition and feeling. It has been made open access,

free for all, by WellBeing International and deposited

in the WBI Studies Repository. For more information,

please contact

wbisr-info@wellbeingintl.org.

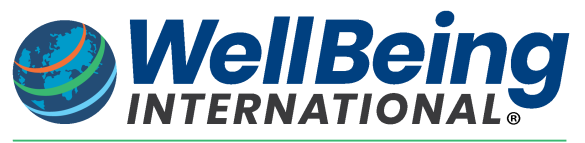

SOLUTIONS FOR PEOPLE, ANIMALS AND ENVIRONMENT 


\title{
Octopus sentience: Three criteria
}

Commentary on Mather on Octopus Mind

\author{
Alix Noël-Guéry \\ Philosophy \\ Université du Québec à Montréal
}

\begin{abstract}
The first question to ask is whether octopuses are sentient, so that, if so, they can be protected. Three consensual criteria to evaluate animal sentience can be applied to the octopus. Octopuses meet all three of them.
\end{abstract}

Alix Noël-Guéry is a Ph.D. student in philosophy of cognitive science at the Université du Québec à Montréal with previous degrees in engineering and music from McGill and Boston University. His research is on creativity, consciousness, states of flow, and the human brain.

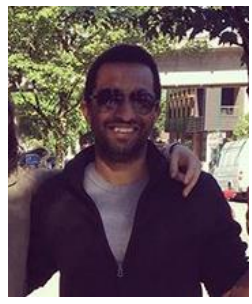

Godfrey-Smith (2016) compares the octopus to the director of a jazz octet. Because of its many capacities, its cognitive capacities are not incommensurable with human ones. However, because of its invertebrate nature and niche, this intriguing animal also seems very far from our species. Does it have a mind? Mather (2019) gives a thorough description of the capacities of the octopus, arguing that it does. But what is a mind?

The notion of "mind" can have many meanings, but before trying to argue about whether the more complex senses of mind apply to octopuses (as mentioned in some commentaries on Mather's target article), surely the most important thing to ascertain is whether they are sentient beings. "Do octopuses feel? Does it feel like something to be an octopus?" Those questions need a consensual answer, especially since what is relevant to their welfare is their sentience, as Correia Caeiro (2019) and King \& Marino (2019) noted.

Mather ends with the statement that all their "capacities need to be directed by a mind." It could be argued that the octopus could have all those capacities without having a mind. It is possible to imagine a robot being able to do what the octopus does without having a mind. On the other hand, it is possible to imagine a human not capable of doing what the octopus can do, yet having a mind. Hence, Mather's conclusion is vulnerable to the traps of the hard problem. To avoid this, a set of consensual criteria is necessary to address the question of cephalopod sentience. Here are three candidates. Each has its strengths and weaknesses, so perhaps they can be combined.

(1) The first criterion is the behavior of the organism when it is wounded: its reaction to what seems to be pain. Indeed, Birch (2017) has stated that this criterion is essential. If an organism feels pain, it is sentient. When this type of behavior is missing, there is a doubt concerning its sentience. 
(2) The second criterion is the presence of a central nervous system. When this is present, it increases the probability of sentience, since most scientists believe the brain generates and integrates sentience.

(3) The third criterion concerns the organism's behavior under anesthesia. There is a link between anesthesia and the absence of sentience. Hence testing the organism's behavior with local and general anesthetics is important.

Does the octopus satisfy those three criteria?

As to the first criterion, many experiments have shown that the octopus reacts to injury as if it is in pain even though its behaviors can be different from those of humans. Godfrey-Smith (2016) wrote: "A recent paper written by Jean Alupay and her colleagues looked carefully at pain-related behaviors, including wound tending, in another species of octopus. There was some reason to expect oddities, because some octopuses, including Alupay's species, nip off their own arms, when necessary, to escape predators. The study found that octopuses who'd had their arms crushed (not too crushed) in an experiment amputated them in some cases, not in all, and they all tended and guarded the injured site for some time. That tending and guarding is, as I discussed, usually seen as an indicator of pain" (p. 87).

As far as the second criterion is concerned, the nervous system of the octopus is very different from the vertebrate and human one. It seems less centralized, but a central nervous system still directs it. Each of the eight legs appears to act quite freely, but the overall system is centralized in the octopus's bi-cephalic brain. Godfrey-Smith (2016) wrote: "The octopuses were unlike the pigeons in that some information did get across; they were unlike us in that it did not get across easily" (p. 73). If pigeons have a central nervous system, octopuses do too.

The third criterion is the organism's response to anesthetics. Seol, Lee, Im, \& Park (2007) showed that "clove oil showed rapid anaesthetic and recovery times in the common octopus." The authors observed a change of body color, slower breathing and less suction with this substance, which is a local anesthetic for humans. Polese, Willow, \& Di Cosmo (2014) also observed behavioral changes with isoflurane (a general anesthetic for humans): "we showed that isoflurane is a good, reversible anesthetic for O. vulgaris, and we developed a method for its use." They observed no movement of the legs after stimuli that would have provoked them without anesthetics.

Since the octopus meets the three criteria, it is highly probable that it is sentient. This essential argument concerning sentience was missing from Mather's target article. Adding this fact to its capacities, it seems quite evident that the octopus has a mind (especially if the definition of mind is sentience combined with those capacities). The moral standing of the octopus should be based first and foremost upon its sentience. Hence, because the three criteria are met, Jacquet, Franks, \& Godfrey-Smith's (2019) argument against farming this cephalopod is sound.

The short, risky life of the octopus may be one cause of its lack of sociability. It seems to be a consequence of the lack of a link between the mothers and their offspring. The females die before their birth. King \& Brown (2019) observed deep-sea octopuses on the coast of California. They live longer. The females have a social life and take care of their offspring. It seems that deepsea waters protect these organisms and increase their sociability and life span. 


\section{References}

Birch, J. (2017). Animal sentience and the precautionary principle. Animal Sentience 16(1).

Correia Caeiro, C. (2019). What we don't know about cephalopods and how to define it. Animal Sentience 26(22).

Godfrey-Smith, P. (2016). Other minds: The octopus, the sea, and the deep origins of consciousness. William Collins.

Jacquet, J., Franks, B., \& Godfrey-Smith, P. (2019). The octopus mind and the argument against farming it. Animal Sentience 26(19).

King, B. J., \& Marino, L. (2019). Octopus minds must lead to octopus ethics. Animal Sentience 26(14).

King, C., \& Brown, J. (2019). Corals, sponges, and an octopus garden in Monterey Bay National Marine Sanctuary. Oceanography 32(1), 52-53, supplement.

Mather, J. (2019). What is in an octopus's mind? Animal Sentience 26(1).

Polese, G., Winlow, W., \& Di Cosmo, A. (2014). Dose-dependent effects of the clinical anesthetic isoflurane on Octopus vulgaris: A contribution to cephalopod welfare. Journal of Aquatic Animal Health 26(4).

Seol, D. -W., Lee, J., Im, S. -Y., \& Park, I. -S. (2007). Clove oil as an anaesthetic for common octopus (Octopus minor, Sasaki). Aquaculture Research 38, 45-49. 